\title{
Afrotropical species of the genus Sculptolobus Yang, van Achterberg \& Chen (Hymenoptera, Braconidae, Braconinae)
}

\author{
Konstantin Samartsev', Cornelis van Achterberg ${ }^{2}$ \\ I Zoological Institute, Russian Academy of Sciences, St Petersburg 199034, Russia 2 Naturalis Biodiversity \\ Center, 2300 RA Leiden, The Netherlands
}

Corresponding author: Konstantin Samartsev (k.samartsev@gmail.com)

Academic editor: V. Gokhman | Received 15 May 2021 | Accepted 15 June 2021 | Published 24 August 2021

http://zoobank.org/E6FDE915-C315-42E2-ABA8-B80CE3B922A2

Citation: Samartsev K, van Achterberg C (2021) Afrotropical species of the genus Sculptolobus Yang, van Achterberg \& Chen (Hymenoptera, Braconidae, Braconinae). In: Proshchalykin MYu, Gokhman VE (Eds) Hymenoptera studies through space and time: A collection of papers dedicated to the $75^{\text {th }}$ anniversary of Arkady S. Lelej. Journal of Hymenoptera Research 84: 301-325. https://doi.org/10.3897/jhr.84.68702

\begin{abstract}
A review of the Afrotropical species of the genus Sculptolobus Yang, van Achterberg \& Chen, 2008 is presented. One species, S. leleji sp. nov., and one subspecies, S. lembaensis harteni ssp. nov., are described. New combinations are proposed for S. bipustulatus (Szépligeti, 1913), comb. nov., S. lembaensis (Cameron, 1912), comb. nov., S. somnialis (Szépligeti, 1913), comb. nov., S. suavis (Szépligeti, 1918), comb. nov., and S. subellipticus (Granger, 1949), comb. nov. Lectotypes are designated for S. lembaensis and S. suavis. For all species descriptions and illustrations are provided together with a diagnostic key.
\end{abstract}

\section{Keywords}

Arabian Peninsula, new combination, new record, new species, new subspecies

\section{Introduction}

Sculptolobus Yang, van Achterberg \& Chen, 2008 is a small genus of Braconinae, the largest subfamily of braconid wasps. It has been recently described from the Oriental part of China, where 5 species have been found. Only two of them (S. zoui Yang, van Achterberg \& Chen, 2008 and S. sulcifer Yang, van Achterberg \& Chen, 2008) have descriptions acceptable for species identification. Oriental species of the genus need a 
separate revision, which require studying the type material deposited in Fujian Agriculture and Forestry University (Fujian, China). In the current article we focused on Afrotropical members of the genus, which were assigned to Bracon Fabricius, 1804 in the past, as well as on species in the material from the Arabian Peninsula collected by Antonius van Harten and deposited in the Naturalis Biodiversity Center (Leiden, The Netherlands).

\section{Material and methods}

\section{Terminology}

Morphological nomenclature follows Quicke (1987) and van Achterberg (1993). The length of fifth segment of the hind tarsus is measured without its pretarsus; the height of the face is measured including the clypeus; first metasomal tergite is measured from its articulating condyle [term applied after Vilhelmsen et al. (2010)]; length of ovipositor sheath is measured from its base.

Abbreviations of morphological terms:

Od maximum diameter of lateral ocellus;

OOL ocular-ocellar distance;

POL postocellar distance;

T1-T6 first-sixth metasomal tergites.

Museum acronyms:

HNHM Hungarian Natural History Museum (Budapest, Hungary);

MNB Museum für Naturkunde (Berlin, Germany);

MNHN Muséum National d'Histoire Naturelle (Paris, France);

RMCA Musée Royal de l'Afrique Centrale (Tervuren, Belgium);

RMNH Naturalis Biodiversity Center (Leiden, The Netherlands);

ZISP Zoological Institute of the Russian Academy of Sciences (Saint Petersburg, Russia).

\section{Taxonomy}

\section{Genus Sculptolobus Yang, van Achterberg \& Chen, 2008}

Sculptolobus van Achterberg, 2006: Chen and Yang 2006: 143 (unavailable: Yu et al. 2016). Sculptolobus Yang, van Achterberg \& Chen, 2008: 95 (type species: Sculptolobus sulcifer Yang, van Achterberg \& Chen, 2008); Samartsev et al. 2017: 786.

Remarks. By a curious incident, the genus Sculptolobus was established two years after its first species had been described. The species S. bannaensis Yang \& Chen, S. tobiasi 
Yang \& Chen, and S. tongmuensis Chen \& Yang have been described in the monograph on Chinese Braconinae (Chen and Yang 2006), but the genus itself was described there without an explicit indication of its novelty and with reference to an article by C. van Achterberg, which has not been published (Yu et al. 2016). Thus, Sculptolobus Chen $\&$ Yang, 2006 is an unavailable name according to the article 16.1 of the International Code of Zoological Nomenclature (ICZN 1999). The valid description of the genus has been published later by Yang et al. (2008).

Diagnosis. In the key to the Old World genera of Braconinae (Quicke 1987), Sculptolobus runs to the couplets 56-74. Further diagnostics of the genus using this key is not possible, because the characters which are variable in species of Sculptolobus are used as diagnostic there (e.g., the relative length of the fore wing veins $2-S R+M$ and 3-SR, degree of development of the medio-longitudinal carina on propodeum and anterolateral areas on T3-T5). The set of 19 genera included in the couplets 56-74 currently is not complete as nine later described Old World genera (excluding Sculptolobus) are suitable for this part of the key. These genera are: Acrocerilia van Achterberg, 1989, Ancilibracon Quicke, 1989, Crinibracon Quicke, 1988, Esengoides Quicke, 1989, Gelasinibracon Quicke, 1989, Scutibracon Quicke \& Walker, 1989, Simplicibracon Quicke, 1988, Stephanobracon Ranjith \& Quicke, 2016, and Uncobracon Papp, 1996. Preparation of a new version of the key to the genera related to Sculptolobus requires a larger-scale revision of many genera and is far beyond the scope of the current article. The diagnostic characters of the genus Sculptolobus are as follows:

Scape with dorsal side longer than ventral side (correctly figured but mistakenly reversed in the original description). Face with weakly differentiated triangular area above clypeus and more or less developed medio-longitudinal elevation (Figs $2 \mathrm{M}, 5 \mathrm{E}, 8 \mathrm{D}$ ), sometimes very prominent and incorporating clypeus (Fig. 1B). Clypeus flattened, with ventral rim (almost) not protruding and with no or weak dorsal carina. Malar suture weakly (Figs 7B, 8B, D) or deeply (Figs 2M, 3D) impressed; malar space not impressed. Notauli deep and often sculptured anteriorly, shallow posteriorly (Figs 2T, 3L). Precoxal sulcus shallowly and widely impressed (Figs 3I, 4K). Fore wing vein $1-S R+M$ straight, vein 1-SR very short. Angle between veins $\mathrm{C}+\mathrm{SC}+\mathrm{R}$ and $1-\mathrm{SR}$ about $70-85^{\circ}$. Base of hind wing membrane evenly setose (Fig. 1G). Fore tibia with thick setae only near its apex (Fig. 8K). Hind tibia without subapical row of thick setae (Fig. 3O). Tarsal claws with protruding basal lobes (Figs 2S, 3O). Metasoma with six coarsely sclerotised tergites. Median area of T2 parallel-sided, incomplete, and laterally delineated by deep furrows. Anterolateral areas of T2 (Fig. 2U: ala) round, convex, separated by crenulate margin and/or furrows, with distal margins bordered by posteriorly converging sublateral carinae (Fig. 2U: slc). Spiracle of T2 located on dorsum of tergite, often far from its lateral margin (Fig. 3I, J: s). Median area of T3 absent. T3-T5 with small anterolateral areas around spiracles separated by crenulate furrows (Fig. 3J: ala). Apical margins of T3-T6 thick, laterally straight (only margin of T3 acutely protruding). Ovipositor sheath $0.5-2.0 \times$ as long as hind tibia; apex of ovipositor with developed dorsal nodus and ventral serration (Figs 2P, 3F, 5L). Head, mesosoma, coxae and most of metasoma granulate or coriaceous. 


\section{Checklist}

S. bannaensis Yang \& Chen, 2006 (Oriental)

S. biareolatus (Granger, 1949) (Afrotropical)

S. bipustulatus (Szépligeti, 1913), comb. nov. (Afrotropical and West Palaearctic)

S. leleji sp. nov. (Afrotropical)

S. lembaensis (Cameron, 1912), comb. nov. (Afrotropical)

S. lembaensis harteni ssp. nov. (Afrotropical)

S. madagascariensis (Szépligeti, 1913) (Afrotropical)

S. somnialis (Szépligeti, 1913), comb. nov. (Afrotropical)

S. suavis (Szépligeti, 1918), comb. nov. (Afrotropical)

S. subellipticus (Granger, 1949), comb. nov. (Afrotropical)

S. sulcifer Yang, van Achterberg \& Chen, 2008 (Oriental)

S. tobiasi Yang \& Chen, 2006 (Oriental)

S. tongmuensis Chen \& Yang, 2006 (Oriental)

S. zoui Yang, van Achterberg \& Chen, 2008 (Oriental)

\section{Key to Afrotropical species of the genus Sculptolobus}

The characters additionally defining taxa under a certain paragraph of a key couplet, but variable in an alternative paragraph, are listed after a dash (-).

1 Dorsal carinae of T1 absent (Figs 3M, 6S, 7O). Spiracle of T2 located close to lateral margin of tergite (Figs 3I, 3J, 7G). Vein 3-SR 0.7-1.4x as long as vein $2-\mathrm{SR}, 0.2-0.5 \times$ as long as vein SR1 (Figs $3 \mathrm{H}, 6 \mathrm{~L}, 7 \mathrm{P}, 8 \mathrm{G}$ ). $-\mathrm{T} 2$ medially $0.9-1.2 \times$ as long as T3 (Figs 3K, 7H, 7R, 8J). Face medially not convex or weakly elevated (Figs 3B, 7C, 7N, 8B), 1.6-1.9× as wide as high (Fig. 3E). OOL 1.3-1.7× POL (Figs 3C, 6Q). Suture between T2 and T3 curved (Figs $3 \mathrm{~K}, 8 \mathrm{~J})$

- $\quad$ Dorsal carinae of T1 developed (complete or incomplete; Figs 1L, 2H, 5H, $6 \mathrm{H})$. Spiracle of T2 located rather remotely from lateral margin of tergite. Vein 3-SR 1.7-2.2x as long as vein 2-SR, $0.5-0.7 \times$ as long as vein SR1 (Figs 1G, 2K, 5F). - T2 medially 1.2-1.5x as long as T3 (Figs 1J, 2U, 4I, $6 \mathrm{~K})$. Face medio-longitudinally weakly elevated (Figs 5C, 6B) to strongly swollen (Figs 1B, 2L), 1.3-1.7× as wide as high. OOL 1.9-2.4× POL (Figs 1C, 5B). Suture between T2 and T3 almost straight (Figs 2U, 4I) or curved (Figs 5J, 6K) .5

2 T2 without posteriorly converging sublateral carinae (Fig. 3K); median area of T2 elongate-triangulate, not separated by furrows. Vein $2-S R+M 0.5 \times$ as long as vein $\mathrm{m}-\mathrm{cu}$ (Fig. 3H). Vein 1-M 1.8-1.9× vein m-cu. Marginal cell about $4 \times$ longer than distance from its apex to apex of wing. Antenna with 32-35 antennomeres. Mesoscutum $0.95-1.00 \times$ as wide as long (dorsal view; 
Fig. 3L). - Mesoscutum evenly setose (Fig. 3L). T2 medially $0.95-1.00 \times$ as long as T3. Fore wing length $2.8-2.9 \mathrm{~mm}$. S. leleji sp. nov. T2 with long strongly converging or S-shaped sublateral carinae (Fig. 7F, H, R); median area of T2 parallel-sided or weakly widened posteriorly, separated by incomplete crenulate furrows. Vein $2-S R+M 1.0-1.5 \times$ as long as vein $\mathrm{m}-\mathrm{cu}$ (Figs 7P, 8G). Vein 1-M 2.4-2.9× as long as vein m-cu. Marginal cell $7-10 \times$ longer than distance from its apex to apex of wing. Antenna with 17-22 antennomeres. Mesoscutum 1.2-1.3× as wide as long (dorsal view; Figs 6P, 8I) 3 Vein 3-SR 2.4x longer than vein $\mathrm{r}, 1.4 \times$ longer than vein $2-\mathrm{SR}, 0.5 \times$ as long as vein SR1 (Fig. 8G). Ovipositor sheath $0.7 x$ as long as hind tibia, $0.22 \times$ as long as fore wing. T2 medially $1.2 \times$ longer than T3 (Fig. 8J). Malar space $0.7 \times$ basal width of mandible (Fig. $8 \mathrm{D}$ ). Longitudinal diameter of eye $3.6 \times$ longer than malar space (anterior view; Fig. 8C). Pterostigma brown. - Median lobe of mesoscutum setose on notauli and posteriorly, anteromedially widely glabrous (Fig. 8I). Fore wing length $2.5 \mathrm{~mm}$

S. subellipticus (Granger), comb. nov.

Vein 3-SR 1.0-1.4x as long as vein $\mathrm{r}, 0.7-1.0 \times$ as long as vein $2-S R, 0.25-0.35 \times$ as long as vein SR1 (Figs 6L, 7P). Ovipositor sheath $0.9-1.1 \times$ as long as hind tibia, $0.3-0.4 \times$ as long as fore wing. T2 medially $0.9-1.1 \times$ as long as T3 (Figs $6 \mathrm{O}, 7 \mathrm{H}, \mathrm{R})$. Malar space at least $0.90-0.95 \times$ basal width of mandible (Fig. $7 \mathrm{~B}$ ). Longitudinal diameter of eye 2.3-2.9 $\times$ longer than malar space (anterior view; Fig. 7A, L). Pterostigma brown with more or less large yellow patch apically. Median lobe of mesoscutum entirely setose or glabrous anteromedially ..........4 Longitudinal diameter of eye 2.6-2.9 $\times$ longer than malar space (anterior view; Fig. 7A). OOL 1.3-1.5× POL (Fig. 6P, Q). Vein 3-SR $0.25-0.35 \times$ as long as vein SR1 (Fig. 6L). Anterolateral areas of T2 often distinctly separated by furrows posteriorly (Fig. 6L). Fore wing length $1.6-2.6 \mathrm{~mm}$.....

S. somnialis (Szépligeti), comb. nov.

Longitudinal diameter of eye $2.3 \times$ longer than malar space (anterior view; Fig. 7L). OOL 1.1× POL (Fig. 7K). Vein 3-SR $0.2 \times$ as long as vein SR1 (Fig. 7P). Anterolateral areas of T2 not separated by furrows posteriorly (Fig. 7R). Fore wing length $2.2 \mathrm{~mm}$ S. suavis (Szépligeti), comb. nov. Ovipositor sheath $1.6-1.7 \times$ as long as hind tibia, $0.5-0.6 \times$ as long as fore wing (Fig. 2A, J). Round anterolateral areas of T2 strongly separated from notum by deep crenulate furrows with complete sharp margins (Fig. 2I, U). - Hind femur 4.7-5.3× longer than wide. Fore wing length 2.6-3.2 mm

S. bipustulatus (Szépligeti), comb. nov.

- Ovipositor sheath $0.5-1.1 \times$ as long as hind tibia, $0.30-0.35 \times$ as long as fore wing (Figs 1A, 4A, 5A). Round anterolateral areas of T2 separated from notum by incomplete sharp crenulate margin and at most shallow crenulate furrows (Figs 1L, 4I, 5J, 6K) 
$6 \quad$ Face medio-longitudinally strongly swollen (incorporating clypeus; Fig. 1B, E). Triangular area above clypeus strongly convex. Longitudinal diameter of eye $2.1 \times$ longer than malar space (anterior view; Fig. 1F). Median area of metanotum rugose (Fig. $1 \mathrm{H})$. - Ovipositor sheath $0.55 \times$ as long as hind tibia, $0.35 \times$ as long as fore wing. Dorsolateral posteriorly converging carinae of $\mathrm{T} 1$ absent. Fore wing length $3.5 \mathrm{~mm}$.....S. biareolatus (Granger)

- $\quad$ Face medio-longitudinally weakly elevated or distinctly swollen, but not incorporating clypeus (Figs 2L, 5C, 6B). Triangular area above clypeus flattened. Longitudinal diameter of eye 2.8-3.4x longer than malar space (anterior view; Figs 2N, 4G, 5D, 6E). Median area of metanotum smooth (simple or with median carina; Figs 2Q, 4L, 5G, 6D)

7 Propodeal spiracle located behind middle of propodeum (lateral view; Fig. 6G). Apical margins of T3-T6 without transverse subapical grooves (Fig. 6K). Dorsolateral impressions of T2 deep. Transverse diameter of eye (dorsal view) about $1.6 \times$ longer than temple (Fig. 6C). Scape brown. Vein 3 -SR about $2.0 \times$ longer than vein $\mathrm{r}$ (Fig. $6 \mathrm{~F}$ )

S. madagascariensis (Szépligeti)

- $\quad$ Propodeal spiracle located at middle of propodeum (Figs 4K, 5I). Apical margins T3-T6 with deep or shallow weakly crenulate transverse subapical grooves (Figs 4I, 5J). Dorsolateral impressions of T2 absent. Transverse diameter of eye (dorsal view) 1.9-2.1× longer than temple (Figs 4D, 5B). Scape brownish yellow or rusty. Vein 3-SR 2.3-2.7x longer than vein $r$ (Figs $4 \mathrm{~J}$, $5 \mathrm{~F})$

Longitudinal diameter of eye $3.4 \times$ longer than malar space (anterior view; Fig. $4 \mathrm{G}$ ). Face $1.4 \times$ as wide as high. Vein $2-\mathrm{SR}+\mathrm{M} 1.4 \times$ longer than vein $\mathrm{m}$-cu, as long as vein r. Vein 2-SR 1.6x longer than vein r. Vein 3-SR 1.7x longer than vein 2-SR. Mesosoma $1.3 \times$ as long as high (Fig. $4 \mathrm{~K}$ ). Notauli almost united posteriorly (Fig. 4F). Pterostigma brown (Fig. 4J). Medio-longitudinal impression in upper half of propodeum deep and crenulate (Fig. 4L). Median area of metanotum (dorsal view) with complete median carina. Precoxal sulcus weakly impressed and rugose anteriorly. Fore wing length $3.2 \mathrm{~mm}$ S. lembaensis (Cameron), comb. nov.

- $\quad$ Longitudinal diameter of eye 2.8-3.0x longer than malar space (anterior view; Fig. 5D). Face $1.5-1.7 \times$ as wide as high. Vein $2-S R+M 0.90-0.95 x$ as long as vein $\mathrm{m}$-cu, $0.65-0.70 \times$ as long as vein $\mathrm{r}$. Vein $2-\mathrm{SR} 1.2 \times$ longer than vein $\mathrm{r}$. Vein 3-SR 2.0-2.2× longer than vein 2-SR. Mesosoma 1.6× as long as high (Fig. 5I). Notauli not united posteriorly (Fig. 5K). Pterostigma yellow (Fig. 5F). Medio-longitudinal impression in upper half of propodeum shallow (Fig. 5G). Median area of metanotum (dorsal view) with incomplete median carina. Precoxal sulcus indistinct. Fore wing length $2.5-2.8 \mathrm{~mm}$....... 


\section{Sculptolobus biareolatus (Granger, 1949)}

Fig. 1

Bracon biareolatus Granger, 1949: 56 (in key), 69 (description); Shenefelt 1978: 1469;

Madl and van Achterberg 2014: 41.

Sculptolobus biareolatus: Samartsev et al. 2017: 786.

Material examined. Holotype. Madagascar • Female; Bekily; Jun. 1936; A. Seyrig leg.; MNHN EY19009.

Distribution. Madagascar (Granger 1949).

Remarks. The redescription of the holotype has been presented in Samartsev et al. (2017).

Sculptolobus bipustulatus (Szépligeti, 1913), comb. nov.

Fig. 2

Bracon bipustulatus Szépligeti, 1913: 597; De Saeger 1943: 375; Shenefelt 1978: 1470;

Quicke 1991: 171 (as a member of the Compsobraconoides genus group).

Microbracon bipustulatus: Brues 1926: 309.

Microbracon recessus Szépligeti sec. Brues 1926: 210 (wrong taxon concept according to De Saeger 1943: 375).

Material examined. Holotype. EтніоріA • Female; Harar; Jun. 1911; O. Kovacs leg.; HNHM Hym. Typ.No.1274.

Other material. (2 females, 1 male). Yemen 1 female; al-Lahima; $1200 \mathrm{~m}$ a.s.l.; 1 Jan. - 9 Apr. 2001; A. van Harten \& A.M. Hager leg.; Malaise trap, no. 5486; RMNH INS.1455939 • 1 male; same data as for preceding; RMNH INS.1455940 • 1 female; same data as for preceding; 16 Oct. - 31 Dec. 2001; Malaise trap, no. 5310; ZISP Hym.KS.0005014.

Distribution. Democratic Republic of Congo (De Saeger 1943), Egypt (Fahringer 1927), Ethiopia (Szépligeti 1913), Yemen (new record). Possibly also South Africa and Tanzania (Brues 1926: 210, as Microbracon recessus Szépligeti, explained in De Saeger 1943: 375).

Description. Female. Fore wing length 2.6-3.2 mm. Head. Width of head (dorsal view) 1.9-2.0x its median length. Transverse diameter of eye (dorsal view) 1.8-2.1× length of temple. OOL 2.6-2.8× Od; POL 1.2-1.4× Od; OOL 1.9-2.3× POL. Longitudinal diameter of eye (lateral view) $1.3-1.4 \times$ its transverse diameter. Face medially weakly swollen, incorporating clypeus, with very high medio-longitudinal carina, 1.3-1.6x as wide as high. Longitudinal diameter of eye 2.5-2.6x height of malar space (anterior view). Malar space as long as base of mandible. Malar suture shallow or deep, 


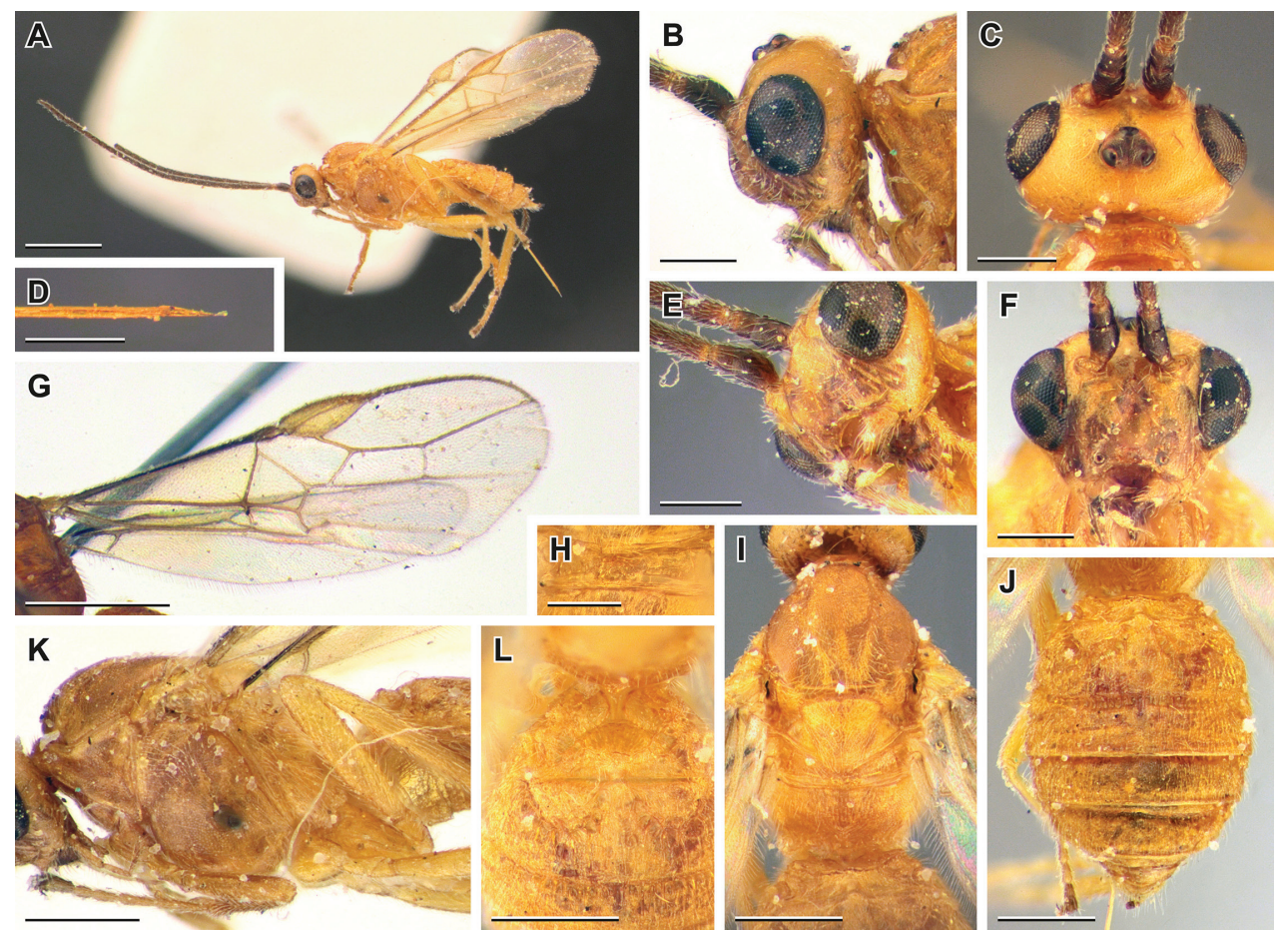

Figure I. Sculptolobus biareolatus (Granger, 1949) (holotype, female, MNHN) A habitus, lateral view $\mathbf{B}$ head, lateral view $\mathbf{C}$ head, dorsal view $\mathbf{D}$ apex of ovipositor $\mathbf{E}$ head, ventrolateral view $\mathbf{F}$ head, anterior view $\mathbf{G}$ fore wing $\mathbf{H}$ metanotum, dorsal view $\mathbf{I}$ mesosoma, dorsal view $\mathbf{J}$ metasoma, dorsal view $\mathbf{K}$ mesosoma, lateral view L T1-T2, dorsal view. Scale bars: $1 \mathrm{~mm}(\mathbf{A}, \mathbf{G}) ; 0.5 \mathrm{~mm}(\mathbf{I}-\mathbf{L}) ; 0.25 \mathrm{~mm}(\mathbf{B}-\mathbf{F}, \mathbf{H})$.

smooth. Width of hypoclypeal depression about $1.3 \times$ distance from depression to eye. Antenna with 26-29 antennomeres, 1.0-1.1× as long as fore wing. First, middle and penultimate flagellomeres $1.9-2.3 \times, 1.8-2.0 \times$, and $2.0-2.2 \times$ as long as wide, respectively. Mesosoma 1.3-1.4x as long as high. Mesoscutum setose on notaulic area and posteriorly, anteromedially widely glabrous. Propodeum with branching medio-longitudinal keel in apical third and at most with weak medio-longitudinal impression basally. Wings. Vein $\mathrm{r}$ arising from basal $0.35-0.50 \times$ of pterostigma. Vein 1-R1 $1.8-2.0 \times$ as long as pterostigma. Marginal cell $7-12 \times$ as long as distance from its apex to apex of wing. Vein 3-SR 2.5-3.2× vein r, 0.6-0.7× vein SR1, 1.9-2.1× vein 2-SR. Vein 2-SR+M $0.55-0.60 \times$ vein $2-S R, 1.0-1.1 \times$ vein $\mathrm{m}$-cu. Vein cu-a weakly or distinctly postfurcal. Legs. Hind femur $4.7-5.3 \times$ longer than wide. Fifth segment of hind tarsus $0.77-0.85 \times$ as long as second segment, $0.40-0.45 \times$ as long as hind basitarsus. Claws with large, protruding and blunt basal lobes. Metasoma. Median length of T1 $0.59-0.62 \times$ its apical width; margin of its median area crenulate. T1 with developed (incomplete or complete) dorsal carinae and laterally compressed median area, with or without sublateral posteriorly converging carinae; dorsolateral carinae of T1 developed. T2 medially $1.2-$ $1.4 \times$ as long as T3; basal width of T2 1.4-1.7x its median length. Anterolateral areas of 


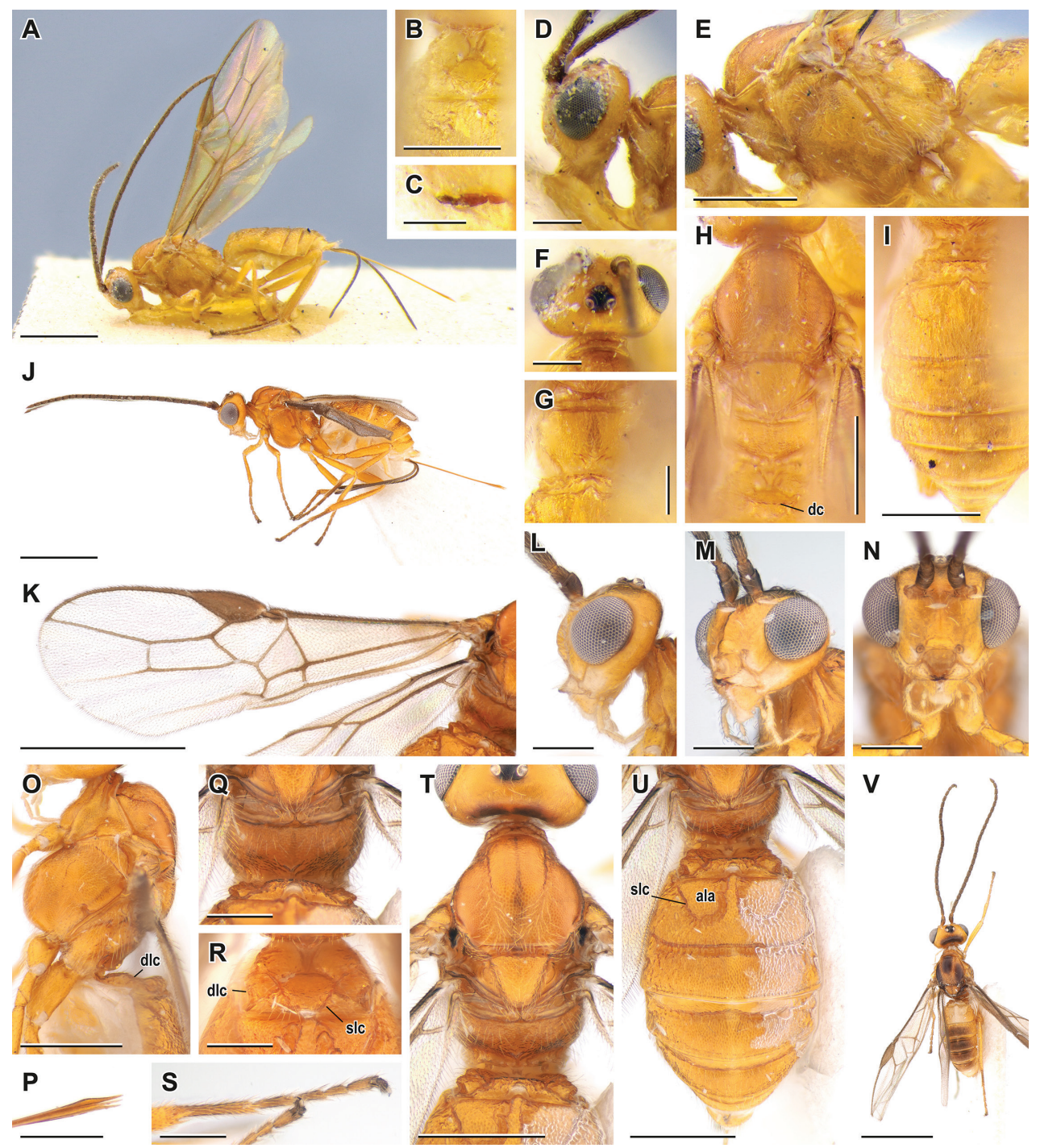

Figure 2. Sculptolobus bipustulatus (Szépligeti, 1913), comb. nov. (A-I holotype, female, HNHM J-Q, S-U female, RMNH R female ZISP $\mathbf{V}$ male, RMNH) A, J habitus, lateral view B, R T1, dorsal view $\mathbf{C}$ tarsal claw $\mathbf{D}, \mathbf{L}$ head, lateral view $\mathbf{E}, \mathbf{O}$ mesosoma, lateral view $\mathbf{F}$ head, dorsal view $\mathbf{G}, \mathbf{Q}$ propodeum, dorsal view $\mathbf{H}, \mathbf{T}$ mesosoma, dorsal view $\mathbf{I}, \mathbf{U}$ metasoma, dorsal view $\mathbf{K}$ fore wing $\mathbf{M}$ head, ventrolateral view $\mathbf{N}$ head, anterior view $\mathbf{P}$ apex of ovipositor $\mathbf{S}$ hind tarsus, anterior view $\mathbf{V}$ habitus, dorsal view. ala anterolateral area dc dorsal carina dlc dorsolateral carina slc sublateral carina. Scale bars: $1 \mathrm{~mm}(\mathbf{A}, \mathbf{J}, \mathbf{K}$, V); $0.5 \mathrm{~mm}(\mathbf{B}, \mathbf{E}, \mathbf{H}, \mathbf{I}, \mathbf{O}, \mathbf{T}, \mathbf{U}) ; 0.25 \mathrm{~mm}(\mathbf{C}, \mathbf{D}, \mathbf{F}, \mathbf{G}, \mathbf{L}-\mathbf{N}, \mathbf{P}-\mathbf{S})$.

T2 round, strongly separated by deep complete crenulate furrows and sharp crenulate margins, delineating not elevated subparallel-sided median area. Dorsolateral impressions of T2 absent; spiracle located behind middle of T2, on dorsum of tergite. Suture between T2 and T3 deep, almost straight, and crenulate. Apical margins of T3-T6 with 
deep or shallow, weakly crenulate transverse subapical grooves. Apical margins of T3T6 laterally straight. Ovipositor sheath $1.6-1.7 \times$ and $0.5-0.6 \times$ as long as hind tibia and fore wing, respectively. Sculpture and colouration. T2-T5 with gradually vanishing weak longitudinal rugosity. Body mainly reddish yellow; tegulae yellow; antenna brown; malar space pale yellow; pterostigma brown or yellowish brown; wing veins brown to yellowish brown; wing membrane weakly darkened, often lighter apically.

Male. Fore wing length $2.2 \mathrm{~mm}$. Width of head (dorsal view) $1.8 \times$ its median length. OOL 2.4× Od; POL 1.6× Od; OOL 1.6× POL. Longitudinal diameter of eye $2.8 \times$ height of malar space (anterior view). Antenna with 25 antennomeres. Marginal cell $15 \times$ as long as distance from its apex to apex of wing. Hind femur $4.5 \times$ longer than wide. Fifth segment of hind tarsus $0.95 \times$ as long as second segment, $0.5 \times$ as long as hind basitarsus. Median length of T1 $0.50 \times$ its apical width. Body with brown patches on vertex, mesoscutum, and T3-T6; T1-T2 pale yellow. Otherwise similar to female.

\section{Sculptolobus leleji sp. nov.}

http://zoobank.org/AD2B62AD-D71E-4747-B19C-3A362B09B2C3

Fig. 3

Material examined. Holotype. YEMEN • Female; $12 \mathrm{~km} \mathrm{NW}$ of Manakhah; $1500 \mathrm{~m}$ a.s.l.; 5 May - 17 Jun. 2002; A. van Harten leg.; Malaise trap no. 6983; RMNH INS.1455961.

Paratype. Yemen • 1 female; same data as for holotype; RMNH INS.1455962.

Distribution. Yemen.

Etymology. This species is named in honour of Prof. A.S. Lelej on the occasion of his $75^{\text {th }}$ anniversary and for his continuous leadership and outstanding contribution to the entomological research in the Russian Far East.

Description. Female. Fore wing length 2.8-2.9 mm. Head. Width of head (dorsal view) $2.0 \times$ its median length. Transverse diameter of eye (dorsal view) 2.2-2.7x longer than temple. OOL $1.7 \times$ Od; POL $1.1 \times$ Od; OOL $1.5 \times$ POL. Longitudinal diameter of eye (lateral view) 1.5-1.6x larger than its transverse diameter. Face medially not swollen, but with high complete medio-longitudinal carina; $1.6 \times$ as wide as high. Longitudinal diameter of eye 2.7-3.1× height of malar space (anterior view). Malar space $0.95-1.00 \times$ base of mandible. Malar suture deep and smooth. Width of hypoclypeal depression 1.1× distance from depression to eye. Antenna with 32-35 antennomeres, $1.0-1.1 \times$ as long as fore wing. First, middle and penultimate flagellomeres 1.7-1.9×, 1.5-1.6×, and 1.7-1.9× as long as wide, respectively. Mesosoma $1.5 \times$ as long as high. Mesoscutum evenly setose. Propodeum with branching medio-longitudinal keel (in apical half only or complete) and at most with a weak medio-longitudinal impression basally. Wings. Vein $\mathrm{r}$ arising from basal $0.4 \times$ of pterostigma. Vein 1-R1 1.6$1.7 \times$ as long as pterostigma. Marginal cell 3.8 $-3.9 \times$ longer than distance from its apex to apex of wing. Vein 3-SR $1.7-2.0 \times$ than vein $\mathrm{r}, 0.36-0.42 \times$ vein SR1, $0.9-1.25 \times$ vein $2-S R$. Vein $2-S R+M \quad 0.33 \times$ vein $2-S R, 0.5 \times$ vein $\mathrm{m}-\mathrm{cu}$. Vein cu-a interstitial. 
A

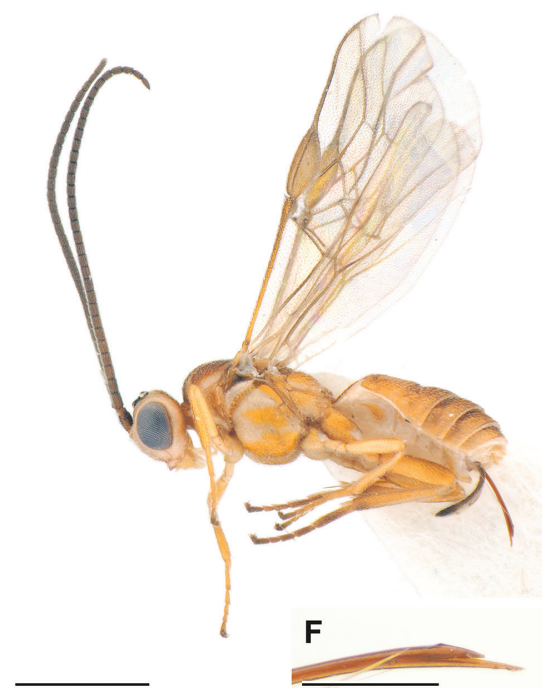

B
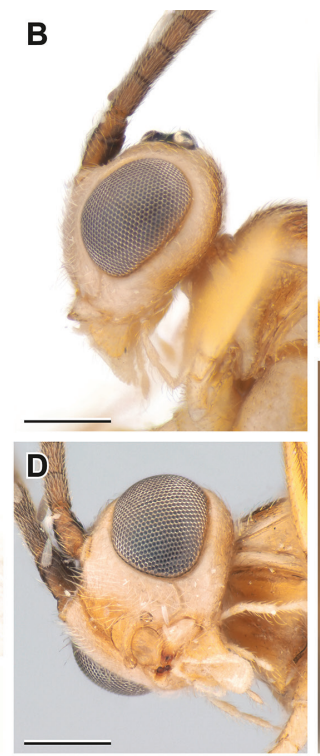

C
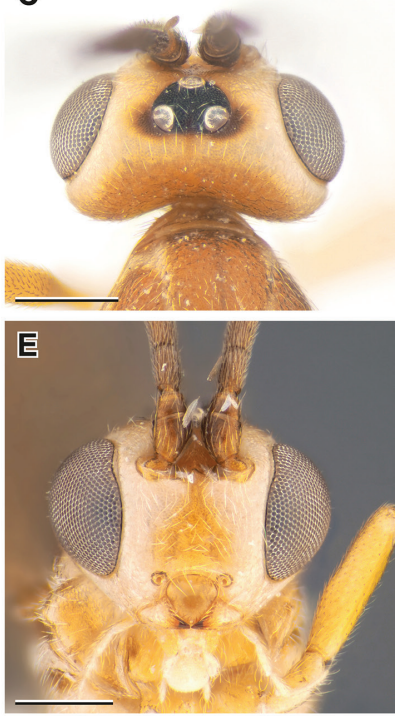

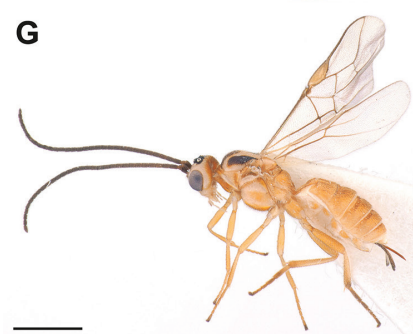

H
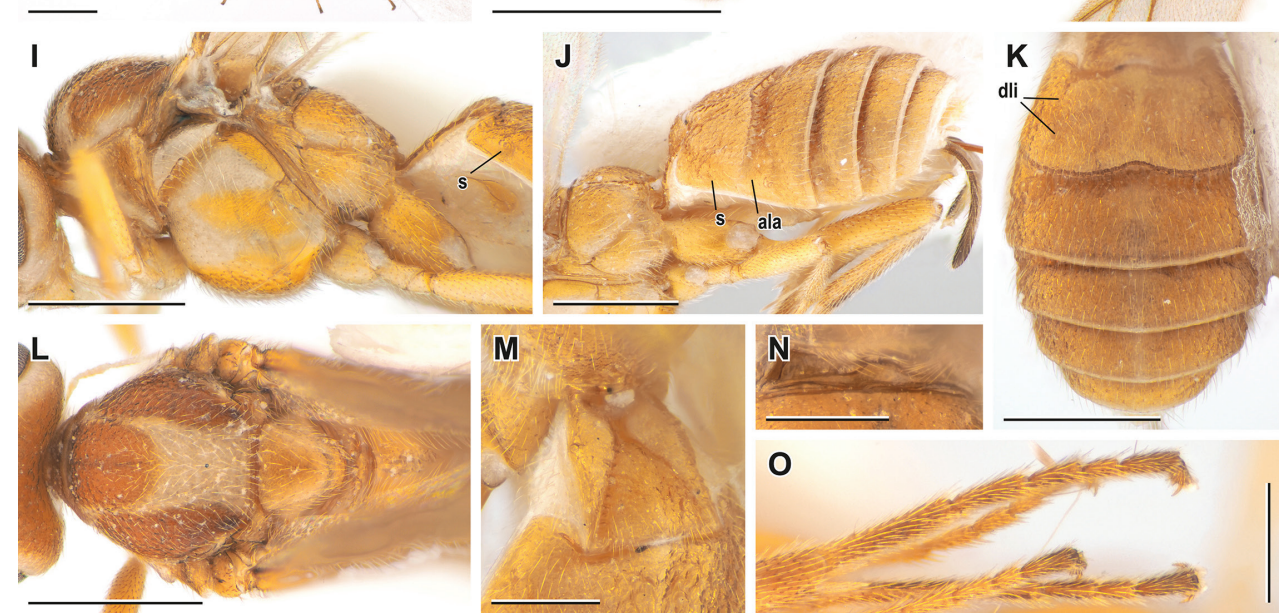

Figure 3. Sculptolobus leleji sp. nov. (A-F, I-O holotype, female, RMNH G, H paratype, female, RMNH) A, G habitus, lateral view $\mathbf{B}$ head, lateral view $\mathbf{C}$ head, dorsal view $\mathbf{D}$ head, ventrolateral view $\mathbf{E}$ head, anterior view $\mathbf{F}$ apex of ovipositor $\mathbf{H}$ fore wing $\mathbf{I}$ mesosoma, lateral view $\mathbf{J}$ metasoma, dorsolateral view $\mathbf{K}$ metasoma, dorsal view $\mathbf{L}$ mesosoma, dorsal view $\mathbf{M}$ T1, dorsolateral view $\mathbf{N}$ metanotum, dorsal view $\mathbf{O}$ hind tarsus. ala anterolateral area dli dorsolateral impression $\mathbf{s}$ spiracle. Scale bars: $1 \mathrm{~mm}(\mathbf{A}, \mathbf{G}$, H); $0.5 \mathrm{~mm}$ (I-L); $0.25 \mathrm{~mm}$ (B-F, M-O). 
Legs. Hind femur 3.6-4.9× longer than wide. Fifth segment of hind tarsus $0.71-0.76 \times$ as long as second segment and $0.39-0.41 \times$ as long as hind basitarsus. Claws with acute angularly protruding basal lobe. Metasoma. Median length of T1 $0.97 \times$ its apical width; margin of its median area crenulate. T1 without dorsal carinae and sublateral posteriorly converging carinae; dorsolateral carinae of T1 weakly separated. T2 medially $0.94-0.97 \times$ as long as third tergite. Basal width of T2 $1.7 \times$ its median length. Median area of T2 weakly elevated, triangle, elongate, weakly separated (no furrows). Anterolateral areas of T2 indistinct or weak, sublateral converging carinae absent. Dorsolateral impressions of T2 shallow, S-shaped, and weakly crenulated; spiracle located in middle of T2 near its lateral margin. Suture between T2 and T3 deep, curved, and crenulate. Apical margins of T3-T6 without transverse subapical grooves. Ovipositor sheath $0.80-0.85 \times$ and $0.20-0.25 \times$ as long as hind tibia and fore wing, respectively. Sculpture and colouration. T2 longitudinally rugose, T3-T5 rugose to granulaterugulose. Body mainly pale yellow to yellow; antenna, ocellar triangle, patch on vertex, three patches on mesoscutum, and hind tarsus brown to dark brown; tegulae yellowish brown; pterostigma yellow or brownish yellow with brown patch apically; wing veins yellowish brown; wing membrane weakly darkened.

Male. Unknown.

Sculptolobus lembaensis (Cameron, 1912), comb. nov.

Fig. 4

Bracon lembaensis Cameron, 1912: 368; Shenefelt 1978: 1501.

Microbracon lembaensis: De Saeger 1943: 376.

Material examined. Lectotype (here designated). Democratic Republic of the ConGO • Female; Kinshasa, Lemba; Apr. 1911; R. Mayné leg.; RMCA ENT_000017836.

Distribution. Democratic Republic of the Congo (Cameron 1912).

Description. Female. Fore wing length $3.2 \mathrm{~mm}$. Head. Width of head (dorsal view) $1.8 \times$ its median length. Transverse diameter of eye (dorsal view) $1.9 \times$ longer than temple. OOL $2.7 \times$ Od; POL $1.4 \times$ Od; OOL $2.0 \times$ POL. Longitudinal diameter of eye (lateral view) $1.4 \times$ its transverse diameter. Face medially convex, but not incorporating clypeus, with complete, high medio-longitudinal carina, $1.4 \times$ as wide as high. Longitudinal diameter of eye $3.4 \times$ height of malar space (anterior view). Malar space $0.87 \times$ base of mandible. Malar suture weakly impressed. Width of hypoclypeal depression $1.2 \times$ distance from depression to eye. Antenna with 30 antennomeres, $1.15 \times$ as long as fore wing. First, middle and penultimate flagellomeres $2.7 \times, 2.2 \times$, and $1.3 \times$ as long as wide, respectively. Mesosoma $1.3 \times$ as long as high. Mesoscutum setose only on notaulic area. Propodeum with branching mediolongitudinal keel in apical two thirds and with deep crenulate medio-longitudinal impression basally. Wings. Vein $\mathrm{r}$ arising from basal $0.4 \times$ of pterostigma. Vein 1-R1 $1.8 \times$ as long as pterostigma. Marginal cell ca. $30 \times$ as long as distance from its apex 


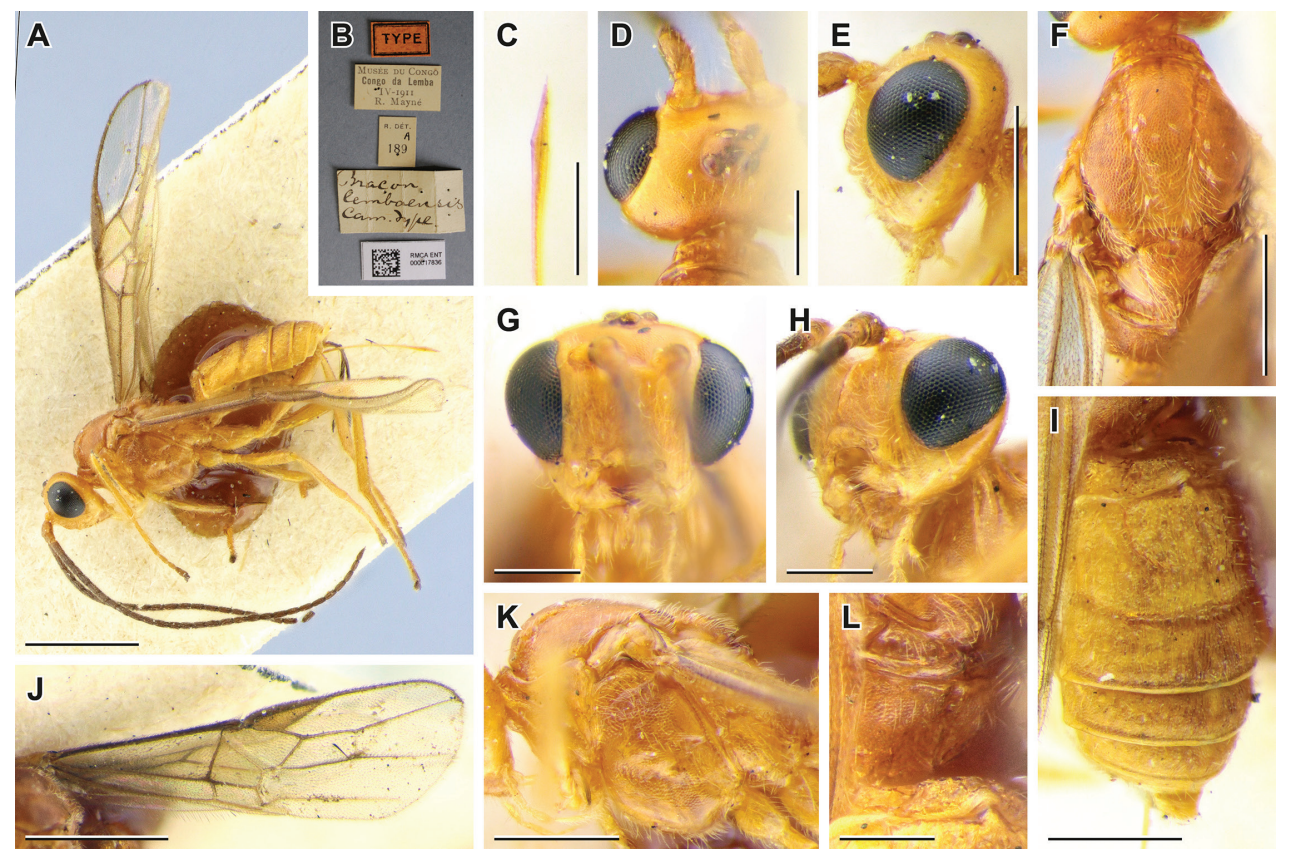

Figure 4. Sculptolobus lembaensis (Cameron, 1912), comb. nov. (lectotype, female, RMCA) A habitus, lateral view B labels $\mathbf{C}$ apex of ovipositor $\mathbf{D}$ head, dorsal view $\mathbf{E}$ head, lateral view $\mathbf{F}$ mesosoma, dorsal view $\mathbf{G}$ head, anterior view $\mathbf{H}$ head, ventrolateral view $\mathbf{I}$ metasoma, dorsolateral view $\mathbf{J}$ fore wing $\mathbf{K}$ mesosoma, lateral view $\mathbf{L}$ propodeum, dorsolateral view. Scale bars: $1 \mathrm{~mm}(\mathbf{A}, \mathbf{J}) ; 0.5 \mathrm{~mm}(\mathbf{E}, \mathbf{K}, \mathbf{I}) ; 0.25 \mathrm{~mm}$ (C, D, F-H, L).

to apex of wing. Vein $3-S R 2.7 \times$ vein $r, 0.53 \times$ vein SR1, $1.7 \times$ vein $2-S R$. Vein $2-\mathrm{SR}+\mathrm{M} 0.65 \times$ vein $2-\mathrm{SR}, 1.4 \times$ vein $\mathrm{m}$-cu. Vein cu-a postfurcal. Legs. Hind femur $4.6 \times$ longer than wide. Fifth segment of hind tarsus $0.8 \times$ as long as second segment, $0.4 \times$ as long as hind basitarsus. Claws with shortly protruding and blunt basal lobes. Metasoma. Median length of T1 $0.65 \times$ its apical width; margin of its median area crenulate. T1 with complete dorsal carinae and without sublateral posteriorly converging carinae; dorsolateral carinae of T1 developed. T2 medially $1.5 \times$ as long as T3; basal width of T2 $1.5 \times$ its median length. Anterolateral areas of T2 strongly separated by sharp crenulate margins and roundly converging sublateral carinae; median area of T2 absent. Dorsolateral impressions of T2 absent; spiracle located in middle of T2, on its dorsum. Suture between T2 and T3 deep, weakly curved, and crenulate. Apical margins of T3-T6 with deep weakly crenulate transverse subapical grooves. Ovipositor sheath as long as hind tibia, $0.34 \times$ as long as fore wing. Sculpture and colouration. T2-T3 longitudinally rugose; T4 rugose to granulaterugulose. Body mainly reddish yellow; mesosoma reddish brown; antenna brown; malar space pale yellow; tegulae brownish yellow; pterostigma brown; wing veins yellowish brown; wing membrane weakly darkened.

Male. Unknown. 


\section{Sculptolobus lembaensis harteni ssp. nov.}

http://zoobank.org/18545A75-55C4-4EAF-91DD-1635F70A4E55

Fig. 5

Material examined. Holotype. Yemen • Female; Lahj; 1 Oct. - 17 Dec. 2001; A. van Harten \& A. Sallum leg.; Malaise trap no. 6254; RMNH INS.1455943.

Paratypes. (3 females, 1 male). Yemen -1 male; al-Kowd; 8-12 Jul. 2001; A. van Harten \& S. Al Haruri leg.; light trap, no. 5750; RMNH INS.1455945 • 1 female; same data as for preceding; 16-20 Aug. 2001; light trap, no. 6141; ZISP Hym. KS.0005015 • 1 female; same data as for holotype; Jan. 2001; Malaise trap, no. 5589; RMNH INS.1298172 • 1 female; same data as for preceding; Apr. 2001; Malaise trap, no. 5594; RMNH INS.1455942.

Distribution. Yemen.

Etymology. The species is named in honour of A. van Harten for his outstanding collecting of arthropods from the Arabian Peninsula and for his impressive book series on the arthropod fauna of the United Arab Emirates.

Description. Female. Fore wing length $2.5-2.8 \mathrm{~mm}$. Head. Width of head (dorsal view) $1.9-2.0 \times$ its median length. Transverse diameter of eye (dorsal view)

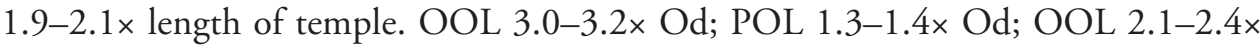
POL. Longitudinal diameter of eye (lateral view) $1.3-1.4 \times$ its transverse diameter. Face medially weakly, but widely elevated, with complete, very high medio-longitudinal carina, $1.5-1.7 \times$ as wide as high. Longitudinal diameter of eye $2.8-3.0 \times$ height of malar space (anterior view). Malar space $0.85-0.90 \times$ base of mandible. Malar suture deep, smooth. Width of hypoclypeal depression 1.1-1.4× distance from depression to eye. Antenna with 28 antennomeres, ca. $1.1 \times$ as long as fore wing. First, middle and penultimate flagellomeres $2.1-2.5 \times, 1.7-1.9 \times$, and $1.9 \times$ as long as wide, respectively. Mesosoma 1.6× as long as high. Mesoscutum setose on notaulic area and posteriorly, anteromedially widely glabrous. Propodeum with short branching medio-longitudinal keel apically and weak medio-longitudinal impression in basal half. Wings. Vein $r$ arising from basal $0.37-0.40 \times$ of pterostigma. Vein $1-\mathrm{R} 11.8-1.9 \times$ as long as pterostigma. Marginal cell 19-26x as long as distance from its apex to apex of wing. Vein $3-S R 2.3-2.5 \times$ vein $r, 0.55-0.60 \times$ vein SR1, 2.0-2.2× vein $2-S R$. Vein $2-S R+M$ ca. $0.6 \times$ vein $2-S R, 0.90-0.95 \times$ as long as vein $\mathrm{m}-\mathrm{cu}$. Vein cu-a weakly postfurcal. Legs. Hind femur $4.4 \times$ longer than wide. Fifth segment of hind tarsus $0.85-0.92 \times$ as long as second segment, $0.5 \times$ as long as hind basitarsus. Claws with shortly protruding and blunt basal lobes. Metasoma. Median length of T1 $0.65-0.75 \times$ its apical width; margin of its median area crenulate. T1 with incomplete dorsal carinae and with weak sublateral posteriorly converging carinae; dorsolateral carinae of T1 developed. T2 medially $1.2-1.4 \times$ as long as T3; basal width of T2 $1.7-1.8 \times$ its median length. Anterolateral areas of T2 round, weakly separated by roundly converging sublateral carinae and shallow crenulate furrows delineating not elevated subparallel-sided median area. Dorsolateral impressions of T2 absent; spiracle located in middle of T2, on dorsum of tergite. Suture between T2 and T3 deep, weakly curved, and crenulate. 
A
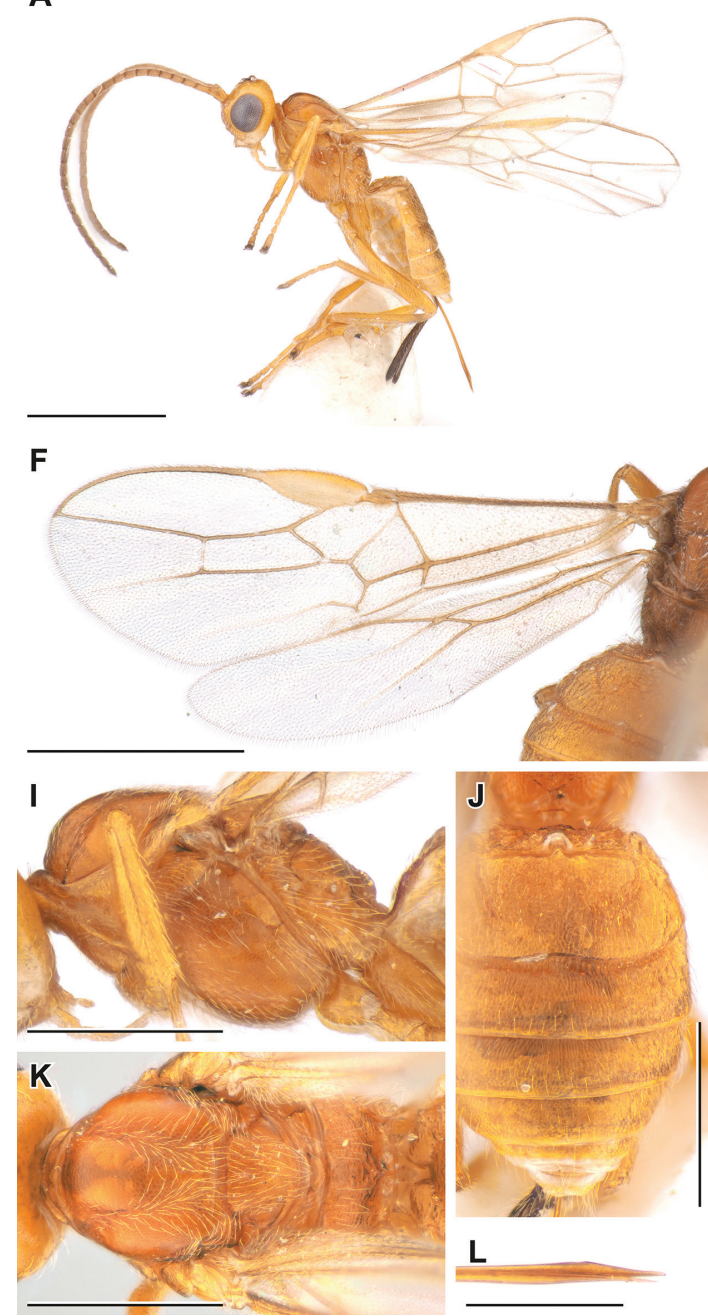
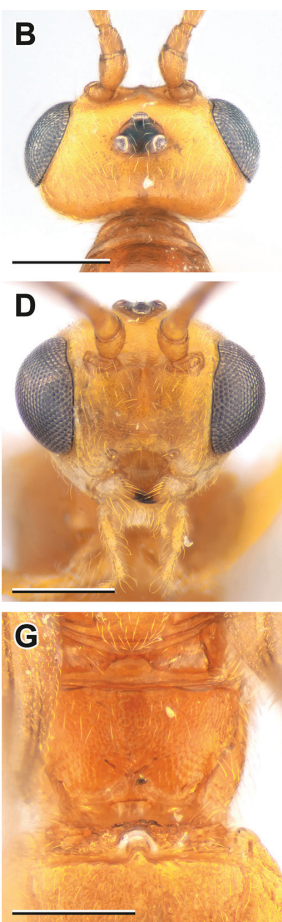

M

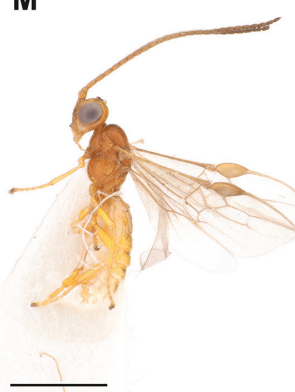

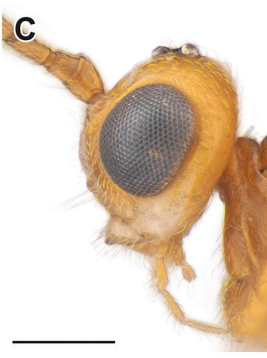
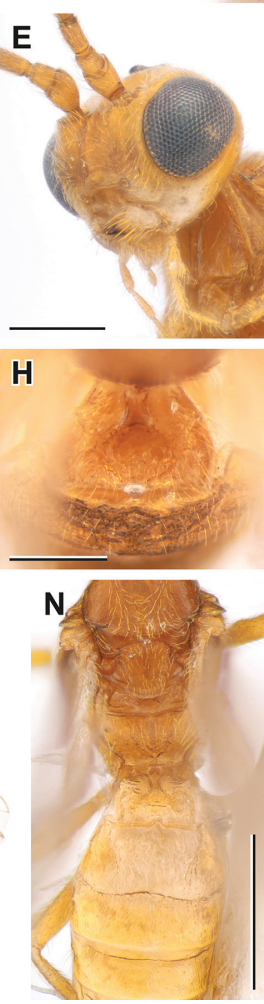

Figure 5. Sculptolobus lembaensis harteni ssp. nov. (A-E, G-L holotype, female, RMNH F paratype, female, RMNH $\mathbf{M}, \mathbf{N}$ paratype, male, RMNH) A, $\mathbf{M}$ habitus, lateral view $\mathbf{B}$ head, dorsal view $\mathbf{C}$ head, lateral view $\mathbf{D}$ head, anterior view $\mathbf{E}$ head, ventrolateral view $\mathbf{F}$ fore wing $\mathbf{G}$ propodeum, dorsolateral view $\mathbf{H}$ T1, dorsal view I mesosoma, lateral view J metasoma, dorsolateral view $\mathbf{K}$ mesosoma, dorsal view $\mathbf{L}$ apex of ovipositor $\mathbf{N}$ propodeum and T1-T3, dorsal view. Scale bars: $1 \mathrm{~mm}(\mathbf{A}, \mathbf{F}, \mathbf{M}) ; 0.5 \mathrm{~mm}(\mathbf{I}-\mathbf{K}$, $\mathbf{N}) ; 0.25 \mathrm{~mm}$ (B-E, G, H, L-N).

Apical margins of T3-T6 with shallow, weakly crenulate transverse subapical grooves. Ovipositor sheath $1.00-1.05 \times$ and $0.31-0.32 \times$ as long as hind tibia and fore wing, respectively. Sculpture and colouration. T2-T3 longitudinally rugose to granulaterugulose. Body mainly reddish yellow, mesosoma reddish brown; malar space pale yellow; tegulae yellow; pterostigma yellow; wing veins pale brown; wing membrane weakly darkened, lighter apically. 
Male. Fore wing length $2.1 \mathrm{~mm}$. Transverse diameter of eye (dorsal view) $2.3 \times$ length of temple. OOL $2.2 \times$ Od; POL $1.1 \times$ Od; OOL $2.0 \times$ POL. Longitudinal diameter of eye $3.9 \times$ height of malar space (anterior view). Malar space $0.75 \times$ base of mandible. Malar suture weak under eye, deep near mandible. Antenna with 27 antennomeres. Mesosoma $1.7 \times$ as long as high. Vein $2-S R+M 0.85 \times$ vein $\mathrm{m}-\mathrm{cu}$. Median length of T1 $0.85 \times$ its apical width. Metasoma yellow with pale yellow T1-T2; pterostigma brownish yellow. Otherwise similar to female.

\section{Sculptolobus madagascariensis (Szépligeti, 1913)}

Fig. 6A-K

Bracon madagascariensis Szépligeti, 1913: 422; Granger 1949: 56 (in key), 71 (redescription); Shenefelt 1978: 1506; Quicke and Koch 1990: 214 (lectotype designation); Madl and van Achterberg 2014: 44.

Microbracon madagascariensis: Brues 1926: 311.

Sculptolobus madagascariensis: Samartsev et al. 2017: 787.

Material examined. Lectotype. MAdAGASCAR 1 female; Fenoarivo Atsinanana; Jul. 1904; S. Voeltzkow leg.; MNB.

Distribution. Madagascar (Szépligeti 1913).

Remarks. The redescription of the lectotype has been presented in Samartsev et al. (2017).

Sculptolobus somnialis (Szépligeti, 1913), comb. nov.

Figs 6L-S, 7A-I

Bracon somnialis Szépligeti, 1913: 598; Shenefelt 1978: 1539 (lectotype designation). Habrobracon somnialis: Quicke 1991: 173.

Microbracon somnialis: Brues 1926: 313.

Material examined. Lectotype. ERITRea - Female; Assab; 1907; K. Katona leg.; HNHM 153287 (formerly Hym.Typ.No.1271).

Paralectotype. ERitrea 1 male; same data as for lectotype; HNHM 153288 (formerly Hym.Typ.No.1272).

Other material. (8 females, 11 males). United Arab Emirates 1 male; AlAjban; 30 Jan. - 26 Feb. 2006; A. van Harten leg.; Malaise trap, no. 10417; RMNH INS.1455948 - 1 male; Sharjah Desert Park; 21-29 Mar. 2005; A. van Harten leg.; light trap, no. 1192; RMNH INS.1455953 - 1 male; same data as for preceding; 13-23 Apr. 2005; light trap, no. 1394; RMNH INS.1455954 • 1 male; same data as for preceding; 1-8 Apr. 2007; light trap, no. 7727-30; RMNH INS.1455952 • 3 males; Wadi Bih dam; 13-30 Apr. 2008; K. Mahmood leg.; light trap, no. 11167; 

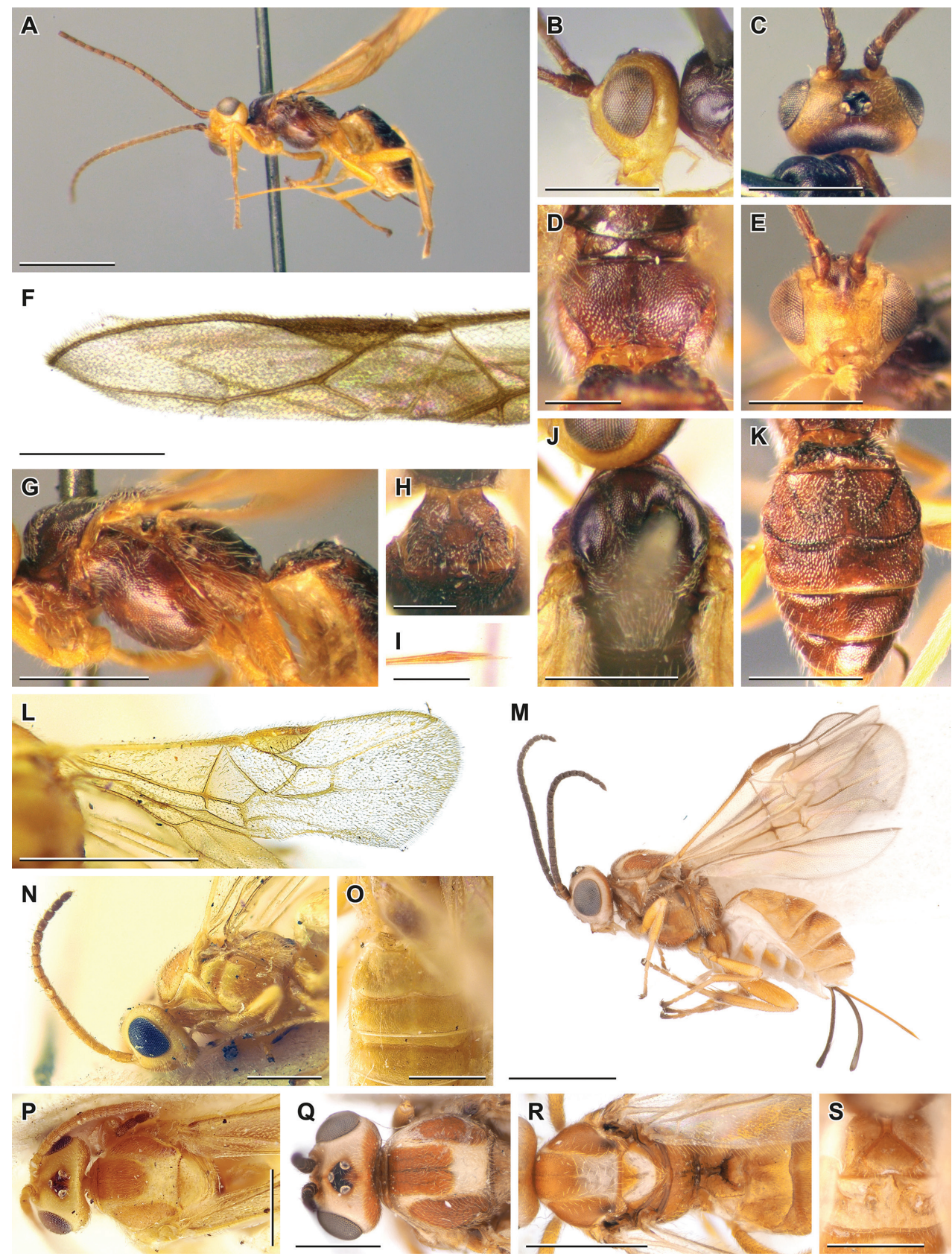

Figure 6. Sculptolobus madagascariensis (Szépligeti, 1913) (A-K lectotype, female, MNB) and S. somnialis (Szépligeti, 1913), comb. nov. (L, N-P lectotype, female, HNHM M, Q-S female, RMNH) $\mathbf{A}, \mathbf{M}$ habitus, lateral view $\mathbf{B}$ head, lateral view $\mathbf{C}$ head, dorsal view $\mathbf{D}$ propodeum, dorsal view $\mathbf{E}$ head, anterior view $\mathbf{F}, \mathbf{L}$ fore wing $\mathbf{G}$ mesosoma, lateral view $\mathbf{H}, \mathbf{S}$ T1, dorsal view $\mathbf{J}, \mathbf{R}$ mesosoma, dorsal view $\mathbf{K}, \mathbf{O}$ metasoma, dorsal view $\mathbf{N}$ head and mesosoma, lateral view $\mathbf{P}, \mathbf{Q}$ head and mesosoma, dorsal view. Scale bars: $1 \mathrm{~mm}(\mathbf{A}, \mathbf{L}, \mathbf{M}) ; 0.5 \mathrm{~mm}(\mathbf{B}, \mathbf{C}, \mathbf{E}, \mathbf{G}, \mathbf{J}, \mathbf{K}, \mathbf{N}-\mathbf{S}) ; 0.25 \mathrm{~mm}(\mathbf{D}, \mathbf{H}, \mathbf{I})$. 
RMNH INS.1298173, INS.1298174, INS.1455947 • 1 male; same data as for preceding; 24 Apr. - 23 May 2007; light trap, no. 11366; RMNH INS.1455951 1 male; Wadi Safad; 2-26 Jan. 2006; A. van Harten leg.; white and yellow pan traps; ZISP Hym.KS.0005016 • 1 male; same data as for preceding; 1-15 Apr. 2006; light trap, no. 11296; RMNH INS.1455949 1 female; same data as for preceding; 22-29 Apr. 2008; light trap, no. 11181-2; RMNH INS.1455946.

Yemen - 1 female; al-Kadan; May 2002; A. van Harten \& A.R. Al Yarimi leg.; light trap, no. 7189; RMNH INS.1455958 2 females; al-Kowd; 8 Jul. 2001-12 Jul. 2001; A. van Harten \& S. Al Haruri leg.; light trap, no. 5750; RMNH INS.1298175, INS.1455955 1 female; same data as for preceding; 21-25 Aug. 2001; light trap, no. 6117; RMNH INS.1455957 • 1 female; same data as for preceding; 1-5 Sep. 2001; light trap, no. 6151; RMNH INS.1298176 • 1 female; same data as for preceding; ZISP Hym.KS.0005017 • 1 female; same data as for preceding; Sep. 2003; light trap, no. 8136; RMNH INS.1455959 • 1 male; Hammam 'Ali; no. 5404; "from coffeeberries (with Ceratitis capitata?)"; RMNH INS.1455960.

Distribution. Eritrea (Szépligeti 1913; Brues 1926), the Republic of Cabo Verde (Papp 2012), United Arab Emirates (new record), Yemen (new record). Incorrectly reported for Ethiopia by Yu et al. (2016), because the species was indicated on the territory of Eritrea (Brues 1926), which separated from Ethiopia in the 1990s.

Description. Female. Fore wing length 1.6-2.6 mm. Head. Width of head (dorsal view) $1.9-2.1 \times$ its median length. Transverse diameter of eye (dorsal view) 1.9-2.3x length of temple. OOL 2.1-2.5× Od; POL 1.6-1.9× Od; OOL 1.3-1.5× POL. Longitudinal diameter of eye (lateral view) $1.3-1.5 \times$ its transverse diameter. Face medially not convex, with high medio-longitudinal carina in upper half, $1.8-1.9 \times$ as wide as high. Longitudinal diameter of eye 2.6-2.9 $\times$ height of malar space (anterior view). Malar space $0.90-0.95 \times$ base of mandible. Malar suture weakly impressed. Width of hypoclypeal depression 1.0-1.1× distance from depression to eye. Antenna with 17-22 antennomeres $0.7-0.8 \times$ as long as fore wing. First, middle and penultimate flagellomeres $1.7-2.2 \times$, 1.4-2.1 times $\times$, and 1.6-2.3× as long as wide, respectively. Mesosoma 1.3-1.5x as long as high. Mesoscutum with variable setosity, entirely setose or widely glabrous on lateral lobes and anteromedially. Propodeum with branching medio-longitudinal keel in apical third and without medio-longitudinal impression basally. Wings. Vein $r$ arising from basal $0.35-0.45 \times$ of pterostigma. Vein 1-R1 $1.3-1.6 \times$ as long as pterostigma. Marginal

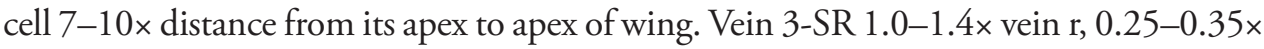
vein SR1, $0.7-1.0 \times$ vein $2-S R$. Vein $2-S R+M 0.5-0.6 \times$ vein $2-S R, 1.1-1.4 \times$ vein $\mathrm{m}$-cu. Vein cu-a interstitial. Legs. Hind femur 3.4-3.6x longer than wide. Fifth segment of hind tarsus $0.75-0.85 \times$ as long as second segment, $0.45-0.50 \times$ as long as hind basitarsus. Claws with acute angularly protruding basal lobes. Metasoma. Median length of T1 $0.6-0.8 \times$ its apical width; margin of its median area crenulate. T1 without dorsal carinae, with laterally compressed median area, with or without sublateral posteriorly converging carinae; dorsolateral carinae of T1 absent or weakly separated apically. T2 medially 0.9$1.1 \times$ as long as T3; basal width of T2 1.9-2.1× its median length. Anterolateral areas of T2 round, strongly separated by incomplete strongly converging or S-shaped crenulate furrows and complete sharp crenulate margin delineating not elevated subparallel-sided 
median area. Dorsolateral S-shaped impressions of T2 absent or deep; spiracle located in middle of T2 near its margin. Suture between T2 and T3 deep, curved, and crenulate. Apical margins of T3-T6 with deep or shallow, weakly crenulate transverse subapical grooves. Ovipositor sheath $1.0-1.2 \times$ and $0.32-0.38 \times$ as long as hind tibia and fore wing, respectively. Sculpture and colouration. T2-T3 sometimes granulate-rugulose to granulate. Body tricoloured. Ground colour of head, mesonotum and metasoma pale yellow; vertex, three patches on mesoscutum, propodeum reddish brown to brown; face, most of mesosoma and legs, and metasoma dorsally yellow to brownish yellow. Tegulae yellowish brown; pterostigma yellow with brown anterior side and patch apically; wing veins yellowish brown; wing membrane weakly darkened, yellowish basally.

Male. OOL 1.7-1.8× Od; POL 1.3-1.7× Od; OOL 1.1-1.2× POL. Face 1.6$1.7 \times$ as wide as high. Longitudinal diameter of eye $2.9-3.2 \times$ height of malar space (anterior view). Malar space $0.75-0.80 \times$ base of mandible. Antenna $0.80-0.95 \times$ as long as fore wing. Vein $2-\mathrm{SR}+\mathrm{M} 1.2-1.7 \times$ vein $\mathrm{m}$-cu. Fifth segment of hind tarsus $0.8-1.0 \times$ as long as second segment, $0.5-0.6 \times$ as long as hind basitarsus. Median length of T1 $0.75-0.95 \times$ its apical width. T2 medially $1.1-1.3 \times$ as long as T3; basal width of T2 $1.7-2.0 \times$ its median length. Median area of 2 weakly elevated. Colouration similar to female, but more contrasting, because of pale yellow patches on scutellum, pronotum, and $\mathrm{T} 1-\mathrm{T} 2$, and brown patches on vertex, mesopleuron, propodeum, and posterior metasomal tergites. Pterostigma brown with large yellow patch basally.

\section{Sculptolobus suavis (Szépligeti, 1918), comb. nov.}

Fig. 7J-R

Bracon suavis Szépligeti, 1918: 189; Shenefelt 1978: 1542.

Microbracon suavis: Brues 1926: 313.

Material examined. Lectotype (here designated). Namibia • Female; "D.S.W. Africa Windhuk" [German South West Africa, Windhoek]; S.V. Krause leg.; MNB.

Distribution. Namibia (Szépligeti 1918).

Description. Female. Fore wing length $2.2 \mathrm{~mm}$. Head. Width of head (dorsal view) $1.9 \times$ its median length. OOL $2.0 \times$ Od; POL $1.9 \times$ Od; OOL $1.1 \times$ POL. Face $1.9 \times$ as wide as high. Longitudinal diameter of eye $2.3 \times$ longer than malar space (anterior view). Malar space $0.9 \times$ base of mandible. Width of hypoclypeal depression $1.1 \times$ distance from depression to eye. Antenna. First flagellomere $2.0 \times$ as long as wide. Mesosoma $1.3 \times$ as long as high. Mesoscutum widely setose on notauli and with sparse setae medio-longitudinally. Wings. Vein $\mathrm{r}$ arising from basal $0.4 \times$ of pterostigma. Vein $1-\mathrm{R} 11.5 \times$ as long as pterostigma. Marginal cell $7.5 \times$ as long as distance from its apex to apex of wing. Vein $3-S R$ as long as vein $r, 0.2 \times$ vein SR1, $0.75 \times$ vein $2-S R$. Vein $2-S R+M \quad 0.55 \times$ vein $2-S R, 1.2 \times$ vein $\mathrm{m}$-cu. Vein cu-a interstitial. Legs. Hind femur $4.1 \times$ longer than wide. Fifth segment of hind tarsus $0.9 \times$ as long as second segment, $0.55 \times$ as long as hind basitarsus. Metasoma. Median length of T1 $0.8 \times$ its apical width. T1 without dorsal carinae and sublateral posteriorly converging carinae. T2 

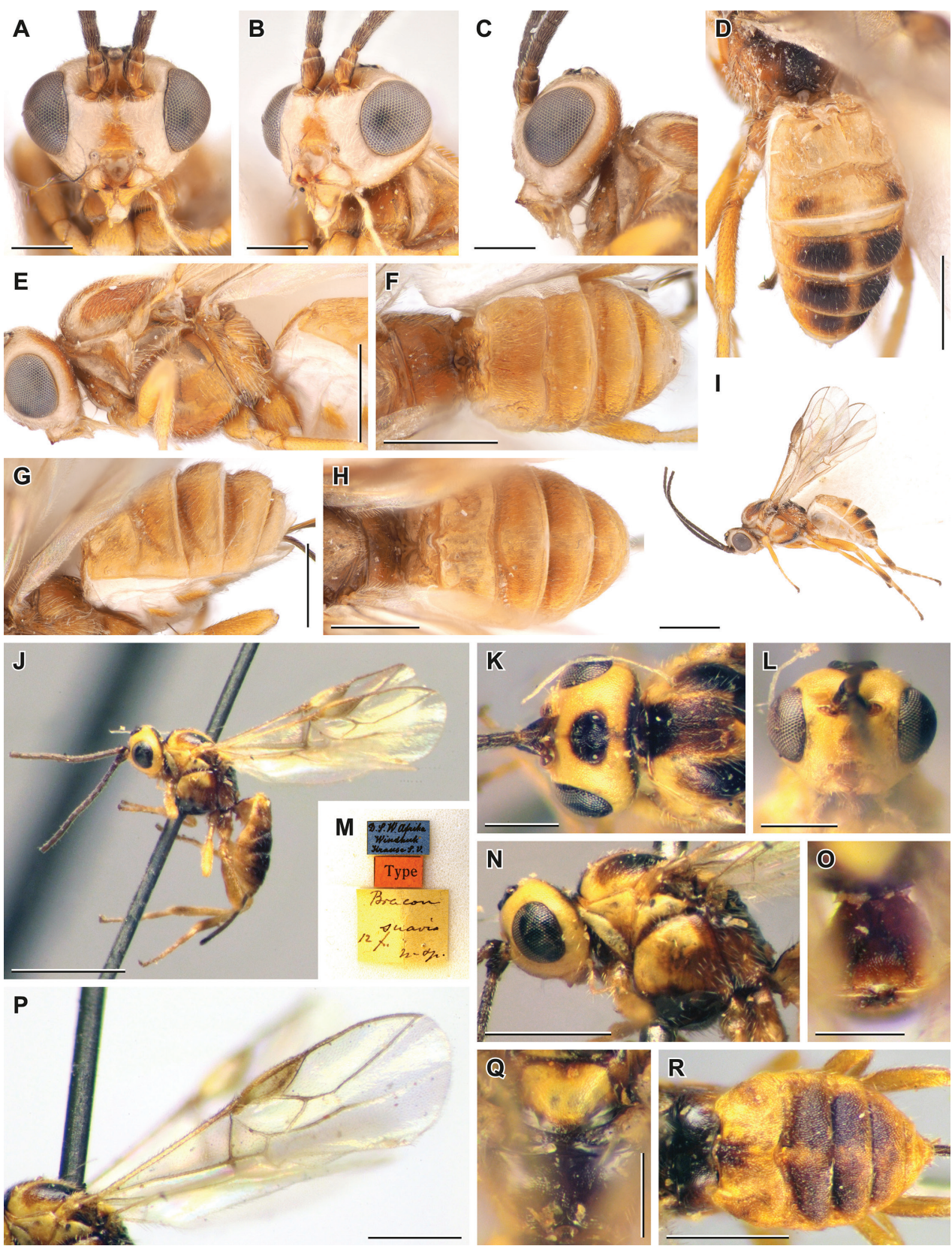

Figure 7. Sculptolobus somnialis (Szépligeti, 1913), comb. nov. (A-C, E, G, H female, RMNH D, I male, RMNH F female, ZISP) and S. suavis (Szépligeti, 1918), comb. nov. (J-R lectotype, female, MNB) $\mathbf{A}, \mathbf{L}$ head, anterior view $\mathbf{B}$ head, ventrolateral view $\mathbf{C}$ head, lateral view $\mathbf{D}, \mathbf{G}$ metasoma, dorsolateral view $\mathbf{E}, \mathbf{N}$ head and mesosoma, lateral view $\mathbf{F}, \mathbf{H}, \mathbf{R}$ metasoma, dorsal view $\mathbf{I}, \mathbf{J}$ habitus, lateral view $\mathbf{K}$ head, dorsal view $\mathbf{M}$ labels $\mathbf{O}$ T1, dorsal view $\mathbf{P}$ fore wing $\mathbf{Q}$ propodeum, dorsal view. Scale bars: $1 \mathrm{~mm}(\mathbf{I}, \mathbf{J})$; $0.5 \mathrm{~mm}(\mathbf{D}-\mathbf{H}, \mathbf{N}, \mathbf{P}, \mathbf{R}) ; 0.25 \mathrm{~mm}(\mathbf{A}-\mathbf{C}, \mathbf{K}, \mathbf{L}, \mathbf{O}, \mathbf{Q})$. 
medially as long as T3; basal width of T2 $1.8 \times$ its median length. Anterolateral areas of T2 incompletely separated by $\mathrm{S}$-shaped sublateral carinae and short subparallel crenulate furrows delineating short weakly elevated median area. Spiracle of T2 located in middle of tergite, near its lateral margin. Suture between T2 and T3 deep, curved and crenulate. Apical margins of T3-T6 without transverse subapical grooves. Ovipositor sheath $0.95 \times$ and $0.30 \times$ as long as hind tibia and fore wing, respectively. Colouration pattern as in S. somnialis.

Male. Unknown.

Remarks. The redescription is based on the photographs of the lectotype.

\section{Sculptolobus subellipticus (Szépligeti, 1913), comb. nov.}

Fig. 8

Bracon subellipticus Granger, 1949: 56 (key), 69 (description); Shenefelt 1978: 1543; Madl and van Achterberg 2014: 47.

Material examined. Holotype. Madagascar • Female; Bekily; 1 Oct. 1936; A. Seyrig leg.; MNHN EY19064.

Distribution. Madagascar (Granger 1949).

Description. Female. Fore wing length $2.5 \mathrm{~mm}$. Head. Width of head (dorsal view) $1.9 \times$ its median length. Transverse diameter of eye (dorsal view) $2.0 \times$ length of temple. OOL 2.2× Od; POL 1.3× Od; OOL 1.7× POL. Longitudinal diameter of eye (lateral view) $1.4 \times$ its transverse diameter. Face medially not convex, with weak mediolongitudinal carina, 1.6x as wide as high. Longitudinal diameter of eye 3.6x length of malar space (anterior view). Malar space $0.7 \times$ base of mandible. Malar suture weakly impressed. Width of hypoclypeal depression $1.3 \times$ larger than distance from depression to eye. Antenna with 22 antennomeres, $0.9 \times$ as long as fore wing. First, middle and penultimate flagellomeres $2.5 \times, 2.1 \times$, and $2.0 \times$ as long as wide, respectively. Mesosoma $1.6 \times$ as long as high. Mesoscutum setose on notaulic area and posteriorly, anteromedially widely glabrous. Propodeum with branching medio-longitudinal keel in apical third and without medio-longitudinal impression. Wings. Vein $\mathrm{r}$ arising from basal $0.45 \times$ of pterostigma. Vein 1-R1 $1.6 \times$ as long as pterostigma. Marginal cell $8.5 \times$ longer than distance from its apex to apex of wing. Vein 3-SR $2.4 \times$ vein $r, 0.5 \times$ vein SR $1,1.4 \times$ vein $2-S R$. Vein $2-S R+M 0.45 \times$ vein $2-S R, 1.0 \times$ vein $\mathrm{m}-\mathrm{cu}$. Vein cu-a weakly postfurcal. Legs. Hind femur $4.0 \times$ longer than wide. Fifth segment of hind tarsus $0.95 \times$ as long as second segment, $0.47 \times$ as long as hind basitarsus. Claws with large, protruding and blunt basal lobes. Metasoma. Median length of T1 $0.8 \times$ its apical width; margin of its median area crenulate. T1 without dorsal carinae and sublateral posteriorly converging carinae; dorsolateral carinae of T1 developed. T2 medially $1.2 \times$ as long as T3; basal width of T2 $1.6 \times$ its median length. Anterolateral areas of T2 round, strongly separated by incomplete crenulate furrows, complete sharp crenulate margin 


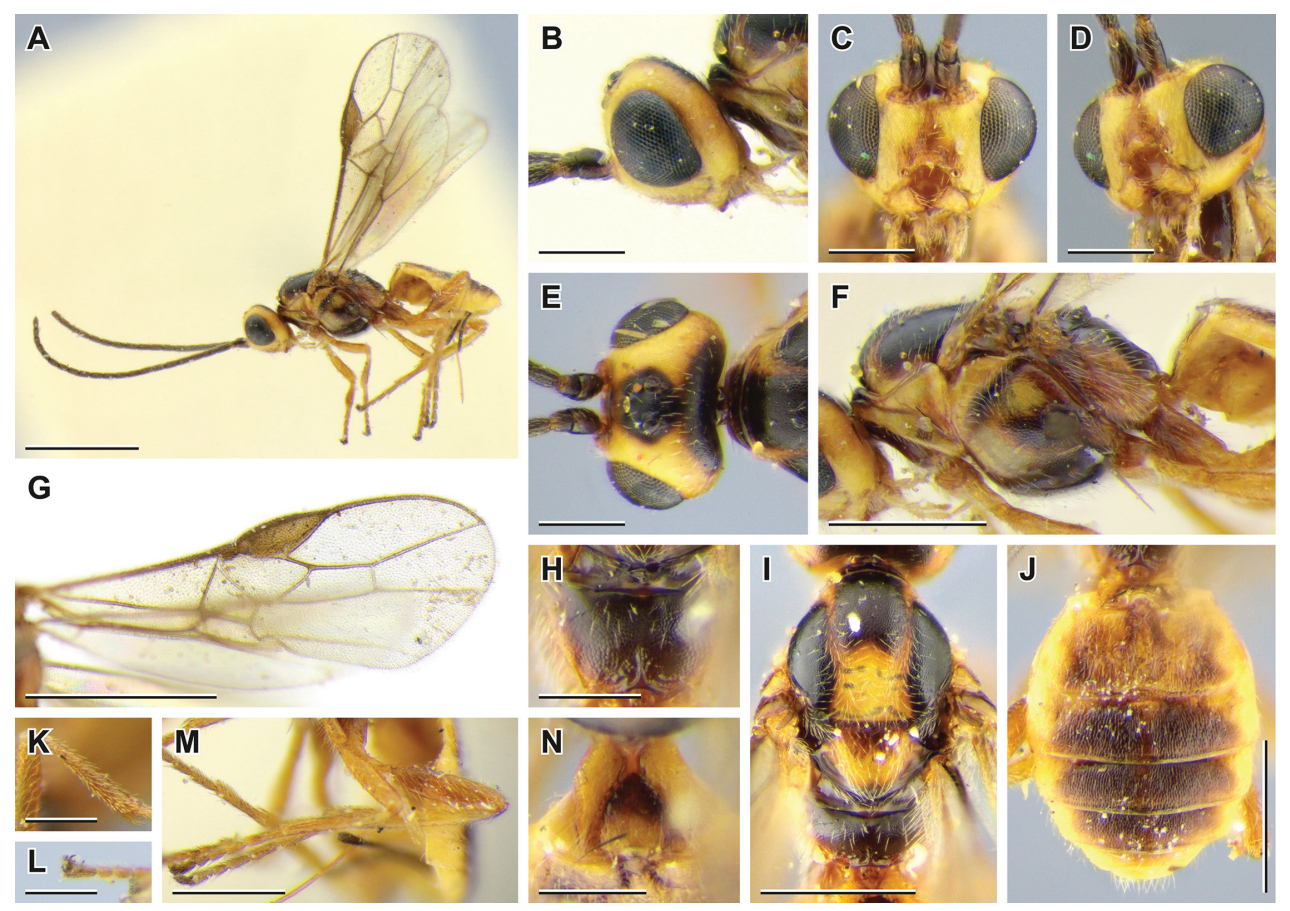

Figure 8. Sculptolobus subellipticus (Granger, 1949), comb. nov. (lectotype, female, MNHN) A habitus, lateral view $\mathbf{B}$ head, lateral view $\mathbf{C}$ head, anterior view $\mathbf{D}$ head, ventrolateral view $\mathbf{E}$ head, dorsal view $\mathbf{F}$ mesosoma, lateral view $\mathbf{G}$ fore wing $\mathbf{H}$ propodeum, dorsal view I mesosoma, dorsal view J metasoma, dorsal view $\mathbf{K}$ fore tibia $\mathbf{M}$ middle and hind legs $\mathbf{N}$ T1, dorsal view. Scale bars: $1 \mathrm{~mm}(\mathbf{A}, \mathbf{G}) ; 0.5 \mathrm{~mm}$ $(\mathbf{F}, \mathbf{M}, \mathbf{I}, \mathbf{J}) ; 0.25 \mathrm{~mm}(\mathbf{B}-\mathbf{E}, \mathbf{H}, \mathbf{K}, \mathbf{L}, \mathbf{N})$.

delineating not elevated subparallel-sided median area, and S-shaped sublateral converging carinae. Dorsolateral impressions of T2 deep, S-shaped, and crenulated; spiracle located in middle of T2, near its lateral margin. Suture between T2 and T3 deep, curved, and crenulate. Apical margins of T3-T6 without transverse subapical grooves. Ovipositor sheath $0.7 \times$ as long as hind tibia and $0.22 \times$ as long as fore wing. Sculpture and colouration. T2-T4 granulate-rugulose to granulate. Coloration pattern similar to $S$. somnialis and S. suavis. Tegulae yellowish brown; pterostigma brown; wing veins pale brown; wing membrane weakly darkened.

Male. Unknown.

\section{Discussion}

In this article, species of the genus Sculptolobus were reported for the first time in the Arabian Peninsula, from where a new species and a new subspecies were described, and the composition of the genus was expanded by five species previously known from Afrotropical region. The genus was found to be rather morphologically uniform 
and well-distinguishable from other taxa of the subfamily. It is most similar to Habrobracon Ashmead [which is considered either a subgenus of the genus Bracon Fabricius or a valid genus; see discussion in Samartsev and Ku (2020: 26)] sharing such characters as the entirely granulate body, details of the fore wing venation (straight vein $1-S R+M$, very short $1-S R$, and long $2-S R+M$ ), absence of thick setae on apex of hind tibia, and presence of incomplete parallel-sided or posteriorly diverging median area on T2 delineated by furrows on its lateral sides. These characters (except for the first one) also characterise the subgenus Sculptobracon Tobias of the genus Bracon. However, although Sculptolobus differs from both similar taxa by the tendency of development of a medio-longitudinal prominence on the face, the presence of malar suture, sublateral posteriorly converging carinae on T1, large anterolateral areas on $\mathrm{T} 2$, and smaller anterolateral areas on T3 and posterior tergites, all these characters are not always developed in certain members of the genus. It is difficult to evaluate the intraspecific variability of characters in the genus, since most of its species are known only by few type specimens. But species for which several specimens are available (for example, S. somnialis) are characterised by a considerable variability, in particular, in the degree of development of depressions on the metasoma and setosity of the mesoscutum (figs $6 \mathrm{R}, 7 \mathrm{~F}-\mathrm{H}$ and $6 \mathrm{P}-\mathrm{R}$, respectively). It should be noted that $S$. somnialis was found to be very similar to S. suavis described from Namibia. However, the differences found for $S$. suavis are still outside the revealed variability of the former species and we therefore refrain from synonymizing $S$. somnialis and S. suavis. We also found several minor differences between Central African specimens of $S$. lembaensis and specimens from the Arabian Peninsula, which resulted in the description of a new subspecies.

The results obtained during the current investigation of Sculptolobus (three out of four species found in the Arabian Peninsula are described from Africa) and those from publications in the near future indicate that studying the braconine fauna of the Arabian Peninsula requires a profound knowledge of the Afrotropical taxa.

\section{Acknowledgements}

We are deeply thankful to Viola Richter and Lukas Kirschey (MNB), Pierre Rasmont (Université de Mons, Belgium), Didier Van den Spiegel and Stéphane Hanot (RMCA), Zoltán Vas (HNHM), and Claire Villemant (MNHN) for the opportunities to study the necessary type material. We are grateful to Tony van Harten (Almada, Portugal) for his extensive collecting of Braconidae in the Arabian Peninsula. We would also like to thank Frederique Bakker (RMNH) for fast and reliable handling of various problems related to the Naturalis collection material. And we are thankful to two anonymous reviewers and to the editor Vladimir E. Gokhman for helpful corrections and suggestions. The study was performed in the frames of the state research project No AAAA-A19-119020690101-6 and supported by the Russian Foundation for Basic Research (grant No 19-04-00027). 


\section{References}

Brues CT (1926) Studies on Ethiopian Braconidae with a catalogue of the African species. Proceedings of the American Academy of Arts and Sciences 61: 206-436. https://doi. org/10.2307/20026158

Cameron P (1912) On the Hymenoptera from Belgian Congo in the Congo Museum, Tervueren. Annales de la Société Entomologique de Belgique 56: 357-401.

Chen J, Yang J (2006) Systematic studies on Braconinae of China. (Hymenoptera: Braconidae). Fujian Science and Technology Publishing House, Fujian, 304 pp.

De Saeger H (1943) Quelques Braconides nouveaux du genre Microbracon. Revue de Zoologie et de Botanique Africaines 36: 361-389.

Fahringer J (1927) Opuscula braconologica. Band 1. Palaearktischen Region. Lieferung 4-6. Opuscula braconologica. Fritz Wagner, Wien, 221-432.

Granger C (1949) Braconides de Madagascar. Mémoires de l'Institut Scientifique de Madagas$\operatorname{car}(\mathrm{A}) 2: 1-428$.

ICZN (1999) International Code of Zoological Nomenclature. Fourth Edition. The International Trust for Zoological Nomenclature, London, 306 pp.

Madl M, van Achterberg C (2014) A catalogue of the Braconidae (Hymenoptera: Ichneumonoidea) of the Malagasy subregion. Linzer biologische Beiträge 46/1: 5-220.

Papp J (2012) Braconid wasps from the Cape Verde Islands 3. Braconinae, Cheloninae, Hormiinae, Microgastrinae and Opiinae (Hymenoptera: Braconidae). Mitteilungen des Internationalen Entomologischen Vereins e.V. (Frankfurt a. Main) 37(3): 117-138.

Quicke DLJ (1987) The Old World genera of braconine wasps (Hymenoptera: Braconidae). Journal of Natural History 21: 43-157. https://doi.org/10.1080/00222938700770031

Quicke DLJ (1991) The non-European Braconinae types of Szépligeti housed in Budapest (Hymenoptera, Braconidae). Annales Historico-Naturales Musei Nationalis Hungarici 83: 169-186.

Quicke DLJ, Koch F (1990) Die Braconinae-Typen der beiden bedeutendsten HymenopterenSammlungen der DDR (Hymenoptera). Deutsche Entomologische Zeitschrift 37(4-5): 213-227. https://doi.org/10.1002/mmnd.19900370403

Samartsev K, Ku D-S (2020) New species of the genera Bracon Fabricius and Syntomernus Enderlein (Hymenoptera, Braconidae, Braconinae) from South Korea. ZooKeys 999: 1-47. https://doi.org/10.3897/zookeys.999.58747

Samartsev KG, Belokobylskij SA, Villemant C (2017) Reclassification of some Bracon species (Hymenoptera: Braconidae: Braconinae) described by Ch. Granger and G. Szépligeti from Madagascar. Annales Zoologici 67(4): 781-794. https://doi.org/10.3161/00034541 ANZ2017.67.4.013

Shenefelt RD (1978) Pars 15. Braconidae 10. Braconinae, Gnathobraconinae, Mesostoinae, Pseudodicrogeniinae, Telengainae, Ypsistocerinae plus Braconidae in general, major groups, unplaced genera and species. In: van Achterberg C, Shenefelt RD (Eds) Hymenopterorum Catalogus. Nova Editio. Dr. W. Junk B.V., Hague, 1425-1872.

Szépligeti G (1913) Neue afrikanische Braconiden aus der Sammlung der Ungarischen National-Museum. Annales Historico-Naturales Musei Nationalis Hungarici 11: 592-608. 
van Achterberg C (1993) Illustrated key to the subfamilies of the Braconidae (Hymenoptera: Ichneumonoidea). Zoologische Verhandelingen 283: 1-189.

Vilhelmsen L, Mikó I, Krogmann L (2010) Beyond the wasp-waist: structural diversity and phylogenetic significance of the mesosoma in apocritan wasps (Insecta: Hymenoptera). Zoological Journal of the Linnean Society 159(1): 22-194. https://doi.org/10.1111/ j.1096-3642.2009.00576.x

Yu DS, van Achterberg C, Horstmann K (2016) Taxapad 2016, Ichneumonoidea 2015. Database on flash-drive. Nepean (Ontario), Canada. 